\title{
Diagnostic criteria for musculoskeletal disorders for use in occupational healthcare or research: a scoping review of consensus- and synthesised-based case definitions
}

Henk F. van der Molen ${ }^{1 *}$, Steven Visser ${ }^{1}$, Jose Hernán Alfonso ${ }^{2}$, Stefania Curti ${ }^{3}$, Stefano Mattioli ${ }^{3}$, David Rempel ${ }^{4}$, Yves Roquelaure $^{5}$, P. Paul F. M. Kuijer ${ }^{1}$ and Sietske J. Tamminga ${ }^{1}$

\begin{abstract}
Background: The aim of this study was to identify case definitions of diagnostic criteria for specific musculoskeletal disorders (MSDs) for use in occupational healthcare, surveillance or research.

Methods: A scoping review was performed in Medline and Web of Science from 2000 to 2020 by an international team of researchers and clinicians, using the Arksey and O'Malley framework to identify case definitions based on expert consensus or a synthesis of the literature. Seven MSDs were considered: non-specific low back pain (LBP), lumbosacral radicular syndrome (LRS), subacromial pain syndrome (SAPS), carpal tunnel syndrome (CTS), lateral or medial elbow tendinopathy, and knee and hip osteoarthritis (OA). Case definitions for occupational healthcare or research were charted according to symptoms, signs and instrumental assessment of signs, and if reported, on work-related exposure criteria.
\end{abstract}

Results: In total, 2404 studies were identified of which 39 were included. Fifteen studies (38\%) reported on nonspecific LBP, followed by knee OA $(n=8 ; 21 \%)$ and CTS $(n=8 ; 21 \%)$. For non-specific LBP, studies agreed in general on which symptoms (i.e., pain in lower back) and signs (i.e., absence of red flags) constituted a case definition while for the other MSDs considerable heterogeneity was found. Only two studies (5\%), describing case definitions for LBP, CTS, and SAPS and lateral and medial elbow tendinopathy respectively, included work-related exposure criteria in their clinical assessment.

Conclusion: We found that studies on non-specific LBP agreed in general on which symptoms and signs constitute a case definition, while considerable heterogeneity was found for the other MSDs. For prevention of work-related MSDs, these MSD case definitions should preferably include work-related exposure criteria.

Keywords: Case definition, Low back pain, Lumbosacral radicular syndrome, Subacromial pain syndrome, Carpal tunnel syndrome, Lateral or medial elbow tendinopathy, Epicondylitis, Knee osteoarthritis, Hip osteoarthritis, Occupational disease, Occupational healthcare

\footnotetext{
* Correspondence: h.f.vandermolen@amsterdamumc.nl

'Department of Public and Occupational Health, Coronel Institute of Occupational Health, Netherlands Center for Occupational Diseases,

Amsterdam Public Health Research Institute, Amsterdam UMC, University of Amsterdam, Meibergdreef 9, Amsterdam, the Netherlands

Full list of author information is available at the end of the article
}

(c) The Author(s). 2021 Open Access This article is licensed under a Creative Commons Attribution 4.0 International License, which permits use, sharing, adaptation, distribution and reproduction in any medium or format, as long as you give appropriate credit to the original author(s) and the source, provide a link to the Creative Commons licence, and indicate if changes were made. The images or other third party material in this article are included in the article's Creative Commons licence, unless indicated otherwise in a credit line to the material. If material is not included in the article's Creative Commons licence and your intended use is not permitted by statutory regulation or exceeds the permitted use, you will need to obtain permission directly from the copyright holder. To view a copy of this licence, visit http://creativecommons.org/licenses/by/4.0/ The Creative Commons Public Domain Dedication waiver (http://creativecommons.org/publicdomain/zero/1.0/) applies to the data made available in this article, unless otherwise stated in a credit line to the data. 


\section{Background}

The accurate assessment of work-related etiological factors related to the onset or worsening of musculoskeletal disorders (MSDs) and diseases is acknowledged as an important research task to provide evidence base for clinical decision-making regarding occupational prevention and return to work [1]. Progress on understanding etiological factors related to the onset or worsening of work-related MSDs may, however, be hampered by variation in MSD case definitions and how these are assessed in occupational cohort studies [2]. As reported by Verbeek in 2012, a case definition consists of a minimum set of symptoms, signs and other data that are needed to establish a diagnosis [3], which can be used in clinical care, health surveillance or research. This variation in case definitions hinders comparison between studies and prevents the combining of studies in meta-analyses. The Network on the Coordination and Harmonisation of European Occupational Cohorts (OMEGA-NET) is an European Cooperation in Science and Technology (EU COST) action aimed at optimising the use of occupational cohorts at the European level [4]. One of its goals is to harmonise occupational exposure and health outcome information. For this reason, we aimed to harmonise case definitions of MSDs in occupational cohort studies.

Another similar initiative has been active since 2018 . The Scientific Committee on work-related MSDs of the International Commission of Occupational Health $(\mathrm{ICOH})$ was tasked with developing international consensus criteria for the clinical assessment of workrelated MSDs [5, 6]. This initiative began with the recruitment of international experts, followed by the development of an overall framework for such criteria and the application of the framework for specific MSDs. The aim is to update and revise for example the criteria document for evaluating the work-relatedness of upperextremity musculoskeletal disorders [7] and non-specific low back pain $[8,9]$. Ultimately, this will lead to a publication on the framework and the publication of consensus criteria for prevalent MSDs.

However, it is currently not known how many MSDs have formulated case definitions and whether there is much variation between these disorder-specific case definitions. At the same time, it is also not known whether work-related exposure criteria are included in these MSD case definitions, if applicable. Consensus regarding case definitions may be agreed upon for example in a formal clinical guideline development process or be based on a Delphi technique, while a synthesis of the literature on case definitions may be based on a systematic review. Since our aim is to scope the literature on case definitions for use in both clinical care as well as for research - an appropriate approach would be to provide an overview of the literature using a scoping review. A systematic review process, which aims to answer a narrow research question, was deemed too limited for our research questions [10]. Performing a scoping review of the literature on criteria for MSDs would also support the ICOH Scientific Committee on MSDs in the development of an overall framework for consensus criteria regarding the occupational clinical assessment of workrelated MSDs. It might also be used as a basis for the OMEGA-NET in reaching consensus on case definitions used in occupational cohort studies.

Specifically, this scoping review aimed to identify case definitions of diagnostic criteria for specific musculoskeletal disorders (MSDs) for use in occupational healthcare, surveillance or research. For the purpose of this scoping review, we included prevalent MSDs and diseases that have been reported to be work-related: nonspecific low back pain (LBP), lumbosacral radicular syndrome (LRS), subacromial pain syndrome (SAPS), carpal tunnel syndrome (CTS), elbow tendinopathies, and knee and hip osteoarthritis (OA) [11-17]. Some of the MSDs included can be considered diseases ('a particular distinctive process in the body with a specific cause and characteristic symptoms') such as osteoarthritis while other MSDs included can be considered disorders ('irregularity, disturbance, or interruption of normal functions') such as LBP. However, to improve readability, musculoskeletal disorder (MSD) is used throughout this scoping review.

\section{Methods}

A scoping review was performed using the Arksey and O'Malley framework [10], which is characterised by a research question that usually leads to the inclusion of studies encompassing various study designs and charting the data in tables/figures. Such reviews do not synthesise the data or perform a quality assessment of the studies included but provide an overview of the literature [10]. In addition, the checklist of Preferred Reporting Items for Systematic Reviews - extension for Scoping Reviews (PRISMA-ScR) was used [18]. A protocol was established before beginning this scoping review, although it was not registered.

\section{Study selection \\ Data sources and search terms}

We systematically searched the electronic database of Medline and Web of Science for studies between 2000 and 26 June 2020. Because this scoping review serves as a basis for further research leading to the development of an overall framework for consensus criteria regarding the clinical assessment of work-related MSDs and for reaching consensus on case definitions used in occupational cohort studies, we were only interested in recent insights. The specific search strategy is described in Additional file 1. 


\section{Article selection}

To be included in this scoping review, a study had to: (i) include diagnostic criteria for any of the following MSDs: non-specific LBP, LRS, SAPS, CTS, lateral or medial elbow tendinopathy, or knee or hip OA; (ii) report diagnostic criteria that were based on a consensusor synthesised-based method; (iii) report a description of MSD diagnostic criteria in terms of symptoms, signs and/or instrumental assessment of signs, e.g. Magnetic Resonance Imaging (MRI), and (iv) full text be available in English, Spanish, German, French, Norwegian, Swedish, Danish, Dutch or Italian. Articles were also included even when work-related exposure criteria were not part of the case definition.

Article selection was performed in three steps. First, titles and abstracts were independently screened by pairs of authors (HvM, JHA, SV, SC, PK, SM and ST) to identify potentially relevant studies by means of the online software tool Rayyan [19]. Second, the full texts of potentially relevant studies were independently assessed for eligibility against the inclusion criteria by the same pairs of authors. Disagreement between these authors about the inclusion of studies occurred for about 6\% (135/ $2404)$ of the articles screened on title and abstract and for about $43 \%(44 / 102)$ of the articles screened on full text. Disagreement about the inclusion based on title and abstract and full text was resolved through in-depth face to face discussion mostly on the fact whether the study really used a consensus- or synthesised based method by HvM, SV and ST.

\section{Charting the data}

A description of the article, the aim of the study (i.e., case definition for clinical practice or research), type of MSD, method (i.e., expert consensus, guideline based on systematic literature review or synthesis of the literature), the case definition of MSD and, if reported, work-related exposure criteria were charted by two authors (SV and ST) on a pre-designed data-charting form. Subsequently, each author checked $100 \%$ of the data charting by the other, which consensus was reached by discussion. Case definitions were collated in accordance with Violante and colleagues (2019) [1, 20]: (i) symptoms, (ii) signs and (iii) instrumental assessment of signs.

\section{Results}

\section{Selected studies}

A PRISMA flow diagram of the study selection process is shown in Fig. 1. In total, 2404 references were retrieved from the two databases and assessed on title and abstract. The full texts of 104 potentially eligible articles were then examined, of which 39 studies met the inclusion criteria, of which 2 were included from experts.
Reasons for excluding studies based on full text are presented in Additional file 2.

\section{Study characteristics}

In total, 39 articles [7, 13, 21-57] described diagnostic criteria for MSD case definitions for non-specific LBP $(n=15,38 \%)[25,27,29,30,37-41,44,47-49,52,54]$, LRS $(n=6,15 \%)[26,32,37,40,47,56]$, SAPS $(n=5$, $13 \%)[7,13,21,31,53]$, CTS $(n=8,21 \%)[7,23,24,33$, $34,36,50]$, lateral and medial elbow tendinopathy $(n=1$, $3 \%)$ [7], and knee $(n=8,21 \%)[22,35,42,43,45,46,55$, $57]$ and hip OA $(n=4,10 \%)[42,45,51,55]$. The charting of these articles is presented in Additional file 3 .

Most studies were conducted in Europe $(n=21,54 \%)$ $[7,13,21,23,25,26,32,33,37-41,45,47,50-52,55-$ 57], reported a synthesis of the literature on case definitions $(n=15,38 \%)[7,21,22,24,27,28,36,39,41,46$, $48-51,57]$, and/or had a clinical aim $(n=32,82 \%)[13$, 21-27, 31-41, 43-50, 52, 53, 55-57], while almost half of the studies reported three or more disciplines that were involved in reaching expert consensus regarding the case definition $(n=19,49 \%)[13,21,24-26,29,31$, 32, 37, 41-43, 45-48, 52, 55, 56] (Additional file 3).

\section{MSD case definitions}

Regarding non-specific LBP (Table 1, Additional file 3), there was general agreement between the studies included that diagnostic criteria for non-specific LBP should consist of pain in the low back without leg pain and absence of specific pathology of the LBP [25, 27, 30, $37-41,47-49,52]$. Some of the studies referred to a specific duration of the symptoms, which varied from $<1$ month to < 12 weeks [30, 37, 38, 40, 47]. Most studies also agreed that imaging should not be recommended $[25,27,38-40,49,52]$. The same was true for LRS with the specification that leg pain should be reported [26, 29, 32, 39, 40, 47, 54, 56]. Additionally, the same was found for chronic LBP, with the duration of pain in the low back referring to chronicity varying from $>6$ weeks to $>12$ weeks [37-41, 44, 47, 49].

The five studies included on SAPS reported that pain in the shoulder in combination with results from tests are needed to identify a patient with SAPS (Table 1, Additional file 3) [7, 13, 21, 31] and that retraction of tendon(s) to the glenoid rim indicate a massive rotator cuff tear [53]. The articles varied on which tests were needed (e.g., painful arc test, Neer's sign test, HawkinsKennedy test, empty can, lift-off and drop arm test) and varied on the use of imaging. For example, some studies were of the opinion that X-ray was needed to assess degenerative changes, while others were of the opinion that ultrasound was needed to exclude a rotator cuff rupture.

More variation was found between the studies included on CTS (Table 1, Additional file 3) [7, 23, 24, 28, 


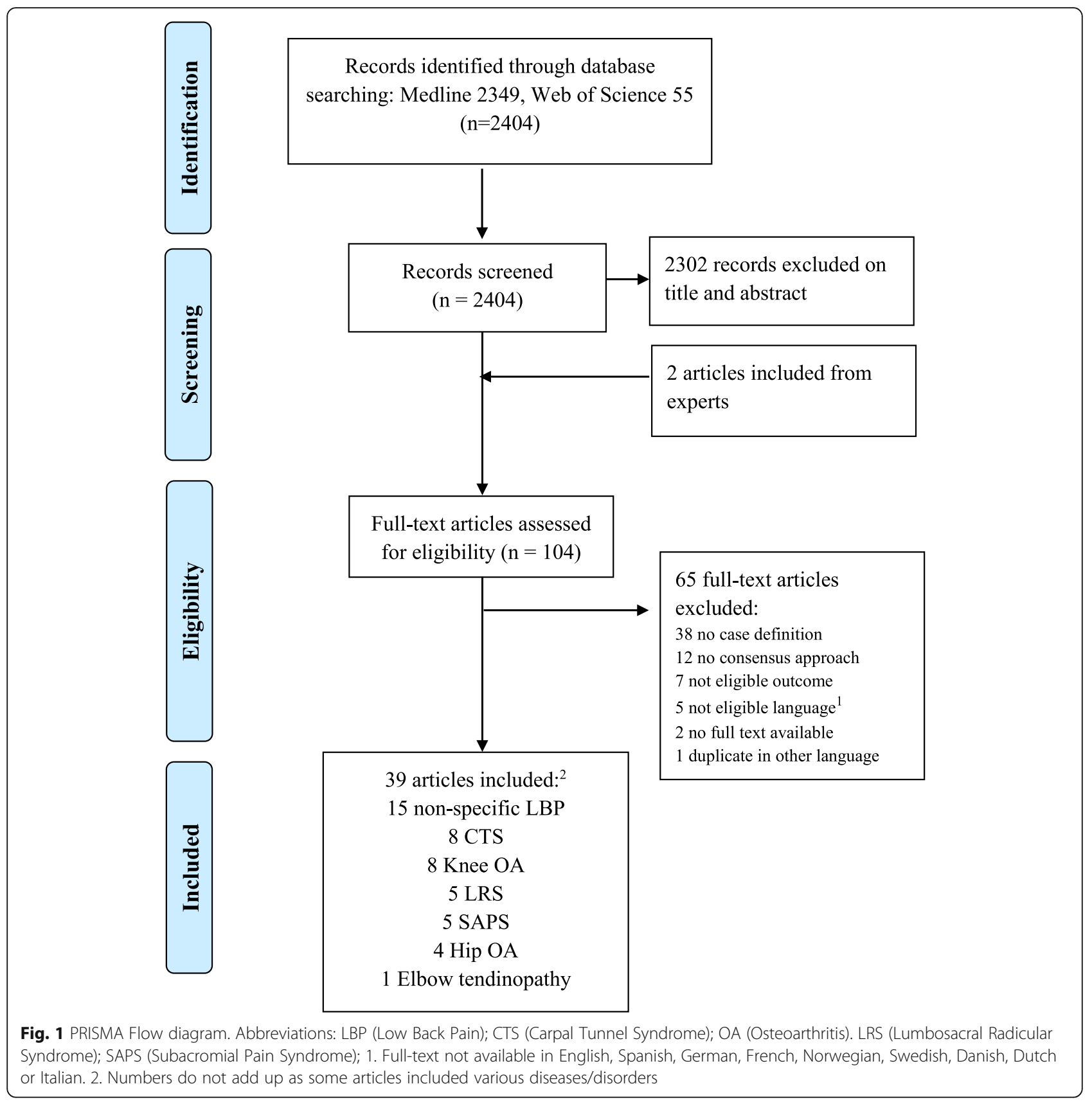

$33,34,36,50]$. Signs varied from none to numbness, pain, tingling, paraesthesia, brachialgia, and nocturnal numbness/paraesthesia in the fingers or hand and/or a combination of these. Determination of symptoms varied from conducting provocation tests such as Tinel's sign and Phalen's test $[7,34,36]$, to not conducting these tests [33], or the assessment of nerve conduction speed, nerve cross-sectional area, and/or latency. Recommended imaging included electrodiagnostic and ultrasound to determine the cross-sectional area, while MRI was not recommended [23, 24, 36, 50].
The only article included on lateral and medial elbow tendinopathy showed that the symptom pain should be directly located around the lateral or medial epicondyle [7]. The pain should be intermittent and activity dependent. Furthermore, the pain should be present at assessment or on at least 4 days during the last 7 days. The signs of lateral elbow tendinopathy were reported as local pain on resisted wrist extension and the signs of medial elbow tendinopathy were reported as resisted wrist flexion (Table 1, Additional file 3). 
Table 1 Collating of all reported symptoms, signs and instrumental assessment of signs of the 39 included studies on MSD case definitions

\begin{tabular}{|c|c|c|c|c|}
\hline \multicolumn{2}{|c|}{ MSD category } & \multirow{2}{*}{$\begin{array}{l}\text { Symptoms } \\
>\text { Pain in low back }[24,26,29,38,47,48,51] \\
<1 \text { month }[46] \text { to }<12 \text { weeks }[36,37,39,40] \text {. } \\
>\text { Muscle tension or stiffness in lower back } \\
{[36,39] .} \\
>\text { Posterior irradiation not below the knee } \\
{[46] .}\end{array}$} & \multirow{2}{*}{$\begin{array}{l}\text { Signs } \\
>\text { No "red flags" (e.g. history of cancer, steroid use, fractures, } \\
\text { infections) }[24,26,36-39,47,48,51] \text {. } \\
>\text { Neurological examination (Lasègue's test and crossing } \\
\text { Lasègue's test) [40]. }\end{array}$} & \multirow{2}{*}{$\begin{array}{l}\text { Imaging } \\
\text { Not } \\
\text { recommended } \\
{[24,26,37-40,48,} \\
51] .\end{array}$} \\
\hline $\begin{array}{l}\text { Non- } \\
\text { specific } \\
\text { LBP }\end{array}$ & Acute & & & \\
\hline & \multirow[t]{4}{*}{ Chronic } & $\begin{array}{l}>\text { Pain in low back }>12 \text { weeks }[28,37-40,43 \text {, } \\
46] \\
>\text { Recurrent: }>2 \text { on an } 11 \text { point NRS for at } \\
\text { least } 24 \mathrm{~h} \text { following a period of at least } 30 \\
\text { days pain free [53]. } \\
>\text { Muscle tension or stiffness in lower back } \\
{[36,39] \text {. }} \\
>\text { Posterior irradiation not below the knee } \\
{[46] .}\end{array}$ & $\begin{array}{l}>\text { No "red flags" (e.g. history of cancer, steroid use, fractures, } \\
\text { infections) }[36-39,43,48] \\
>\text { Neurological examination (Lasègue's test and crossing } \\
\text { Lasègue's test) [40]. }\end{array}$ & $\begin{array}{l}\text { Not } \\
\text { recommended } \\
{[37-40,43,48]}\end{array}$ \\
\hline LRS & & $\begin{array}{l}>\text { Pain in low back }[38,39]<1 \text { month }[46] \text {. } \\
>\text { Muscle tension or stiffness or weakness in } \\
\text { lower back }[39,55] \text {. } \\
>\text { Posterior irradiation below the knee or } \\
\text { anterior to the thigh }[46] . \\
>\text { Radicular pain in } 1 \text { lower limb }[25,31,55] \text {. }\end{array}$ & $\begin{array}{l}>\text { One or more positive neurological test indicating nerve } \\
\text { root irritation or neurological deficit (e.g. a positive Lasègue's } \\
\left.\text { test at } 60^{\circ}\right)[25,31,38,39,55] \text {. } \\
>\text { Finger-floor distance of }>25 \mathrm{~cm} \text { [55]. } \\
>\text { Neurological signs (e.g. incontinence) [55]. }\end{array}$ & $\begin{array}{l}\text { Not } \\
\text { recommended } \\
{[39,55] \text {. }}\end{array}$ \\
\hline SAPS & & $\begin{array}{l}>\text { Shoulder pain }[7,13,20,30] \text { worsened by } \\
\text { active elevation }[7,13] \text {. } \\
>\text { Weakness of shoulder muscles [20,30]. } \\
\gg \text { Stiffness of shoulder joint [30]. } \\
\gg \text { Loose or unstable shoulder [30]. } \\
>\text { Painful clicking, grinding or clunking in the } \\
\text { shoulder [30]. }\end{array}$ & $\begin{array}{l}\text { > Positive (pain or weakness) on one or more specific tests } \\
\text { (e.g. Neer's sign test or Painful arc test) [7, 13, 20,30]. } \\
>\text { Retraction of tendon(s) to the glenoid rim, measured in } \\
\text { either the coronal or axial plane, and/or } \geq 67 \% \text { of the greater } \\
\text { tuberosity exposed, measured in the sagittal plane, diagnosed } \\
\text { either with MRI or intraoperatively [52]. }\end{array}$ & $\begin{array}{l}\text { Useful after } 6 \\
\text { weeks of } \\
\text { symptoms [13]. } \\
\text { MRI [52] }\end{array}$ \\
\hline CTS & & $\begin{array}{l}\gg \text { (Nocturnal) numbness of digits I, II or III [7, } \\
22,32,33,35,49] \text {. } \\
>\text { Pain in hand, wrist and forearm }[7,49] \text {. } \\
>\text { Weakness/atrophy of thenar musculature } \\
\text { [33]. } \\
>\text { Tingling feelings in digits I, II or III }[22,49] \text {. }\end{array}$ & $\begin{array}{l}>\text { Positive on provocative tests (e.g. Tinel's sign or Phalen's } \\
\text { test) }[7,33,35] \text {. } \\
\text { 27 Nerve conduction examination of the median nerve [22, } \\
\text { 27, 35, 49]: } \\
\text { a. Sensitive neurography: }>8 \mathrm{~m} / \mathrm{s} \text { compared with ulnar nerve } \\
\text { [22] } \\
\text { b. Distal motor latency: }>4.2 \mathrm{~ms} \text { compared with ulnar nerve } \\
\text { [22]. } \\
>\text { Cut off }>8,5 \mathrm{~mm} 2 \text { of median nerve cross-sectional area } \\
\text { [23]. }\end{array}$ & NR \\
\hline \multicolumn{2}{|c|}{$\begin{array}{l}\text { Elbow } \\
\text { tendinopathy: } \\
\text { Lateral or medial }\end{array}$} & $\begin{array}{l}\triangleright \text { Activity dependent pain around the lateral } \\
\text { or medial epicondyle [7]. }\end{array}$ & $\begin{array}{l}\gg \text { Local pain on resisted wrist extension (lateral) or on } \\
\text { resisted wrist flexion (medial) [7]. }\end{array}$ & NR \\
\hline \multirow[t]{2}{*}{$\mathrm{OA}$} & Hip & $\begin{array}{l}>\text { Hip pain }[41,44,50,54] \text {. } \\
>\text { Restricted range of motion of the hip [50]. } \\
>\text { Morning stiffness }<1 \mathrm{~h} \text { in hip [50]. }\end{array}$ & $\begin{array}{l}\gg \text { Joint space narrowing }[44,50,54] . \\
>\text { Kellgren-Lawrence grade } \geq 2[41] . \\
>\text { Osteophytes }[44,54] .\end{array}$ & $\begin{array}{l}\text { X-Ray }[41,44,50, \\
54] .\end{array}$ \\
\hline & Knee & $\begin{array}{l}>\text { Knee pain }[21,34,41,42,44,45,54,56] . \\
>\text { Morning stiffness }<30 \text { min in knee }[21,34 \text {, } \\
42,54,56] \text {. } \\
>\text { Crepitus in knee }[21,34,42,54,56] . \\
>\text { Restricted range of motion of the knee } \\
{[56] .}\end{array}$ & $\begin{array}{l}>\text { Bone enlargement or osteophytes }[21,44,54,56] \\
>\text { No palpable warmth }[21,54] \text {. } \\
>\text { Joint space narrowing }[44] \text {. } \\
>\text { Synovial fluid; clear and viscous; leukocyte count < 2000/ } \\
\text { ml [21, 34]. } \\
>\text { Kellgren-Lawrence grade }>0 \text { [45] or } \geq 2[41,42] \text {. }\end{array}$ & $\begin{array}{l}\text { X-Ray }[21,34,41 \\
42,44,45,54,56]\end{array}$ \\
\hline
\end{tabular}

Abbreviations: MSD (Musculoskeletal Disorder), LBP (Low Back Pain), NRS (Numeric Rating Scale), LRS (Lumbosacral Radicular Syndrome), SAPS (Subacromial Pain Syndrome), MRI (Magnetic Resonance Imaging), CTS (Carpal Tunnel Syndrome), OA (Osteoarthritis)

All of the studies included on hip OA reported hip pain with three out of four of the studies reporting hip pain combined with joint space narrowing. All recommended X-ray to assess degeneration using the KellgrenLawrence scale (Table 1, Additional file 3) [42, 45, 51, 55]. More variation was found on knee OA. Symptoms ranged from knee pain to knee pain combined with stiffness, reduced function, swelling, cracking and/or grinding movement [22, 35, 42, 43, 45, 46, 55, 57]. Signs ranged from none to an extensive list of alterations in the knee, such as bony enlargement. Five of the eight studies on knee OA agreed on using X-ray to assess degeneration using the Kellgren-Lawrence scale [22, 35, $42,43,45,46]$. 


\section{Work-related exposure criteria}

In one study [44] discussing chronic LBP the following working exposure criteria were reported: long-term spinal heavy burden, excessive rotation, or vibration.

In another study [7] discussing case definitions for SAPS, CTS and lateral and medial elbow tendinopathy, work-related exposure criteria were included in the clinical assessment of the case definition. Work-related exposure criteria for SAPS included: 1) postures: i) with hands behind the back, ii) where hand reaches to opposite part of the trunk, iii) with extreme rotation, iv) where the arm is unsupported by the body for several minutes; 2) elevation movements of the upper arm in comparison with those of the trunk; 3) high repetitions of movements of the upper extremity; and 4) a combination of more than average force and one of the movements or postures mentioned.

For CTS, work-related exposure criteria included: extreme wrist postures, handling (vibrating) tools, high repetition of wrist movements, high forces for the hands, and combination of postures/movements and forces [7].

Finally, for lateral and medial elbow tendinopathy work-related exposure criteria included: extreme flexion of the elbow, posture with extended elbows, posture with extreme pronation or supination of the elbow, high repetition of movements of the elbow, grasping or lifting of objects with high forces and/or combination of postures, movements and forces [7].

\section{Discussion}

In this scoping review, we found that studies on nonspecific LBP, agreed in general on which symptoms (i.e., pain in lower back) and signs (i.e., absence of red flags) constitute a case definition, while considerable heterogeneity was found for the other MSDs. Only two studies, describing case definitions for CTS, SAPS and lateral and medial elbow tendinopathy, included work-related exposure criteria in their clinical assessment.

\section{Comparison with the literature and recommendations for future research}

While this scoping review identified various clinical and research settings in which consensus has been reached or the literature has been synthesised regarding case definitions, some knowledge gaps were found. Case definitions of diagnostic criteria for MSDs may differ depending on the setting and purpose. A setting may be a clinical or an occupational epidemiological research context, while the purpose may consist of prevention (including screening activities), prognosis or treatment. When considering a clinical setting we agree with Genevay et al. that case definitions for clinical practice require high sensitivity and high specificity, while case definitions for occupational epidemiological research mainly require higher specificity. High specificity is required, given that the inclusion of false positive cases need to be avoided in occupational epidemiological research [32] as it may influence the identification of personal- and work-related risk factors. However, prevention-related studies among workers may require just higher sensitivity for precautious reasons.

Case definitions for research and for workers' health surveillance also need to consider practicalities such as costs, the burden of completing questionnaires, and the availability of resources. This need for balance resulted in some studies providing a minimal and an optimal case definition depending on its research purpose [30]. For example, Dionne et al. reported a minimal case definition consisting of two questions, one on back pain and one on severity, and an optimal case definition that was based on the minimal definition with additional questions covering frequency, duration of symptoms and severity, as well as a question covering sciatica and a question excluding other causes [30].

Case definitions aiming to assess the work-relatedness of a disorder/disease in association with workers' health surveillance [58] or financial compensation may need higher sensitivity, given the financial costs involved. In both situations, a symptom questionnaire with high disorder/disease sensitivity and a follow-up medical examination may be the best option [58].

Considering the purpose of the case definition, those aimed at prevention in clinical care or research could encompass greater heterogeneity since sensitivity is less important given that this heterogeneity has a limited effect on identifying personal and work-related risk factors $[59,60]$. For treatment at an individual level, a higher sensitivity is needed, especially in the case of high costs, detrimental side effects or the limited availability of resources. This is reflected, for example in the fact that case definitions used in a clinical care more often included imaging (Additional file 3).

Work-related exposure criteria in the clinical assessment of a case definition require more attention in future research $[61,62]$. We only found two studies that reached consensus for work-related MSDs diagnostic case definitions [7, 44], although recently there are more studies available that address work-related risk factors for specific MSDs (e.g., [2, 11, 28, 6367]). The International Classification of Diseases (ICD-11) of the World Health Organisation (WHO) [68] includes expert-based criteria for work-related diseases $[68,69]$. These expert-based criteria, in combination with the data charted in this scoping review, could serve as a basis for a Delphi study aiming for the harmonisation of these case definitions, focussing on research aimed at prevention of work-related disorders/diseases. 
In comparison with previous research on expert consensus methods in other fields such as medical education, we found that consensus methods were not standardised and not transparently reported; for example, no detailed data were provided about the participating experts [70]. Furthermore, we also found those studies which reported on a consensus method, most often did not provide a definition of consensus a priori, in terms of envisioned content and format of the intended outcome [70, 71]. Finally, previous research found that rating scales influence the outcome of these consensus methods [72] but less is known about which factors, such as tacit professional collective knowledge, affect the outcome of these consensus methods among experts. To that end, more research is needed on consensus methods themselves as well as criteria to improve the reporting of these consensus methods [71]. When that is achieved, future reviews on this topic might be able to only include high quality studies.

\section{Strengths and limitations}

One strength of this review is that it encompassed a variety in reported consensus or synthesis approaches providing an overview of case definitions for the MSDs included, as reported in peer-reviewed medical journals. This appeared especially important for our research question, as we found that heterogeneous study designs were used to reach consensus or to synthesise the literature on case definitions. Another strength was the international research team of whom most have been involved in these case definition developments. Four limitations should be noted. First, we may have overlooked some relevant studies, since our search strategy was limited to one database and the Web of Science. Second, we may have overlooked some relevant studies since in some studies it was arbitrary whether or not the authors applied a consensus- or synthesized-based method. Third, in a scoping review, quality assessments are not performed, because the literature is charted without critical appraisal of the studies included [10]. However, additional file 3 shows that the studies included differed in the amount of information they provided regarding their research methods. In addition, it was not always made clear whether consensus was based on the consultation of experts from various disciplines, although the involvement of multiple disciplines was considered an essential element in reaching consensus regarding case definition [73]. Finally, when reviewing the studies included there was a large variety in consensus methods used and how well these methods were described [71].

\section{Conclusions}

We found that studies on non-specific LBP, agreed in general on which symptoms (i.e., pain in lower back) and signs (i.e., absence of red flags) constitute a case definition, while considerable heterogeneity was found for the other MSDs. This scoping review can serve as a starting point for systematic reviews in disease specific case definitions with an initial broader inclusion process followed by a data synthesis of included studies with low risk of bias in order to distill the best evidence. But also, for future research in which expert consensus can be reached on a disorder/disease-specific case definition for a specific setting, such as patient care or occupational health research, and given a specific purpose, such as treatment or prevention of these (work-related) MSDs. For prevention purposes, case definitions on workrelated MSDs should also include work-related exposure criteria.

\section{Supplementary Information}

The online version contains supplementary material available at https://doi. org/10.1186/s12891-021-04031-z.

Additional file 1. Search strategy.

Additional file 2. Reasons for excluding studies based on full text.

Additional file 3. Study characteristics and MSD case definitions of included studies.

\section{Abbreviations}

MSDs: Musculoskeletal disorders; LBP: Low back pain; LRS: Lumbosacral radicular syndrome; SAPS: Subacromial pain syndrome; CTS: Carpal tunne syndrome; OA: Osteoarthritis; OMEGA-NET: Network on the Coordination and Harmonisation of European Occupational Cohorts; EU COST: European

Cooperation in Science and Technology; ICOH: International Commission of Occupational Health; PRISMA-SCR: Systematic Reviews - extension for

Scoping Reviews; MRI: Magnetic Resonance Imaging; ICD-11: The

International Classification of Diseases; WHO: World Health Organisation

Acknowledgments

We would like to thank Joost G Daams for his help with the search strategy.

Authors' contributions

HvM, SV, PK, ST: manuscript preparation. HvM, JHA, SV, SC, PK and SM: article selection. SV and ST: charting of data. All authors interpreted the data and critically revised the manuscript. All authors have read and approved the manuscript.

Funding

This publication is based upon work from COST Action CA16216, supported by COST (European Cooperation in Science and Technology).

Availability of data and materials

All data generated or analysed during this study have been included in this published article.

Ethics approval and consent to participate

Not applicable.

Consent for publication

Not applicable.

Competing interests

The authors declare that they have no competing interests.

Author details

${ }^{1}$ Department of Public and Occupational Health, Coronel Institute of Occupational Health, Netherlands Center for Occupational Diseases, Amsterdam Public Health Research Institute, Amsterdam UMC, University of Amsterdam, Meibergdreef 9, Amsterdam, the Netherlands. ${ }^{2}$ Department of Occupational Medicine and Epidemiology, National Institute of Occupational 
Health, Oslo, Norway. ${ }^{3}$ Department of Medical and Surgical Sciences, University of Bologna, Bologna, Italy. ${ }^{4}$ Division of Occupational and Environmental Medicine, University of California, San Francisco, USA. ${ }^{5}$ Univ Angers, CHU Angers, Univ Rennes, Inserm, EHESP, Irset (Institut de recherche en santé, environnement et travail), UMR_S 1085, F-49000 Angers, France.

Received: 20 July 2020 Accepted: 28 January 2021

Published online: 11 February 2021

\section{References}

1. Violante FS, editor. Exposure level assessment for causal attribution of MS diseases and occupational exposure limits to prevent MS diseases and disorders PREMUS: Bologna; 2019. http://www.premus2019.com/wpcontent/uploads/2019/09/PREMUS-2019-Programme-30.08.19.pdf

2. Descatha A, Albo F, Leclerc A, Carton M, Godeau D, Roquelaure Y, et al. Lateral Epicondylitis and physical exposure at work? A review of prospective studies and meta-analysis. Arthritis Care Res. 2016;68(11):1681-7.

3. Verbeek J. When work is related to disease, what establishes evidence for a causal relation? Saf Health Work. 2012;3(2):110-6.

4. Turner MC, Mehlum IS. Greater coordination and harmonisation of European occupational cohorts is needed. Occup Environ Med. 2018;75(7): 475-6.

5. Rempel D, Walker-Bone K, Descatha A, Seidler A, Kuijer P. Developing International Criteria for Work-Related Musculoskeletal Diseases: An Initiative of the Committee on Work-related Musculoskeletal Disorders of $\mathrm{ICOH}$. Premus 2019, Bologna http://www.premus2019.com/wp-content/uploads/2 019/09/PREMUS-2019-Programme-30.08.19.pdf 2019.

6. Van der Molen HF. Comparison of diagnostic criteria for occupational upper extremity disorders between countries. Occup Environ Med. 2018; 75(Suppl 2):A254

7. Sluiter JK, Rest KM, Frings-Dresen MH. Criteria document for evaluating the work-relatedness of upper-extremity musculoskeletal disorders. Scand J Work Environ Health. 2001;27(Suppl 1):1-102.

8. Kuiper Il, Burdorf A, Frings-Dresen MH, Kuijer PP, Spreeuwers D, Lotters FJ, et al. Assessing the work-relatedness of nonspecific low-back pain. Scand J Work Environ Health. 2005;31(3):237-43.

9. Kuiper Jl, Burdorf A, Frings-Dresen MH, Kuijer PP, Spreeuwers D, Lötters F, Miedema HS. Criteria for determining theWork-relatedness of nonspecific low-back pain. Amsterdam: Amsterdam coronel Institute of Occupational Health, Amsterdam UMC - AMC; 2004.

10. Arksey H, O'Malley L. Scoping studies: towards a methodological framework. Int J Soc Res Methodol. 2005;8:19-32.

11. Lotters F, Burdorf A, Kuiper J, Miedema H. Model for the work-relatedness of low-back pain. Scand J Work Environ Health. 2003;29(6):431-40.

12. Griffith LE, Hogg-Johnson S, Cole DC, Krause N, Hayden J, Burdorf A, et al. Low-back pain definitions in occupational studies were categorized for a meta-analysis using Delphi consensus methods. J Clin Epidemiol. 2007;60(6): 625-33.

13. Diercks R, Bron C, Dorrestijn O, Meskers C, Naber R, de Ruiter T, et al. Guideline for diagnosis and treatment of subacromial pain syndrome: a multidisciplinary review by the Dutch Orthopaedic association. Acta Orthop. 2014;85(3):314-22.

14. Work-related Carpal Tunnel Syndrome Diagnosis and Treatment Guideline 2017. Washington, USA: Washington State department of labor and Industries. ; 2017.

15. Tawa N, Rhoda A, Diener I. Accuracy of clinical neurological examination in diagnosing lumbo-sacral radiculopathy: a systematic literature review. BMC Musculoskelet Disord. 2017;18(1):93.

16. Linaker $\mathrm{CH}$, Walker-Bone K. Shoulder disorders and occupation. Best Pract Res Clin Rheumatol. 2015;29(3):405-23.

17. Hallman DM, Rasmussen CDN, Jorgensen MB, Holtermann A. Time course of neck-shoulder pain among workers: a longitudinal latent class growth analysis. Scand J Work Environ Health. 2018;44(1):47-57.

18. Tricco AC, Lillie E, Zarin W, O'Brien KK, Colquhoun $H$, Levac D, et al. PRISMA extension for scoping reviews (PRISMA-SCR): checklist and explanation. Ann Intern Med. 2018;169(7):467-73.

19. Ouzzani M, Hammady H, Fedorowicz Z, Elmagarmid A. Rayyan — a web and mobile app for systematic reviews. Syst Rev. 2016;5(210). https:// systematicreviewsjournal.biomedcentral.com/articles/10.1186/s13643-016-03 84-4\#citeas.
20. Curti S, M Mattioli S, Bonfiglioli R, Farioli A, Violante F.S. Elbow tendinopathy and occupational biomechanical overload: a systematic review with bestevidence synthesis. J Occup Health. 2021 Accepted for publication.

21. Alqunaee M, Galvin R, Fahey T. Diagnostic accuracy of clinical tests for subacromial impingement syndrome: a systematic review and metaanalysis. Arch Phys Med Rehabil. 2012;93(2):229-36.

22. Alshami AM. Knee osteoarthritis related pain: a narrative review of diagnosis and treatment. Int J Health Sci (Qassim). 2014;8(1):85-104.

23. Assmus H, Antoniadis G, Bischoff C, Haussmann P, Martini AK, Mascharka Z, et al. Diagnosis and therapy of carpal tunnel syndrome - Guideline of the German societies of Handsurgery, neurosurgery, neurology, Orthopaedics, clinical neurophysiology and functional imaging, plastic, reconstructive and aesthetic surgery, and surgery for traumatology. Handchir Mikrochir P. 2007; 39(2):276-88.

24. Cartwright MS, Hobson-Webb LD, Boon AJ, Alter KE, Hunt CH, Flores VH, et al. Evidence-based guideline: neuromuscular ultrasound for the diagnosis of carpal tunnel syndrome. Muscle Nerve. 2012;46(2):287-93.

25. Chenot JF, Greitemann B, Kladny B, Petzke F, Pfingsten M, Schorr SG. Nonspecific low Back pain. Dtsch Arztebl Int. 2017:114(51-52):883-90.

26. Cid J, De La Calle JL, Lopez E, Del Pozo C, Perucho A, Acedo MS, et al. A modified Delphi survey on the signs and symptoms of low back pain: indicators for an interventional management approach. Pain Pract. 2015; 15(1):12-21

27. Dagenais S, Tricco AC, Haldeman S. Synthesis of recommendations for the assessment and management of low back pain from recent clinical practice guidelines. Spine J. 2010;10(6):514-29.

28. Descatha A, Dale AM, Franzblau A, Coomes J, Evanoff B. Comparison of research case definitions for carpal tunnel syndrome. Scand J Work Environ Health. 2011;37(4):298-306.

29. Deyo RA, Dworkin SF, Amtmann D, Andersson G, Borenstein D, Carragee $E_{\text {, }}$ et al. Focus article: report of the NIH task force on research standards for chronic low Back pain. Eur Spine J. 2014;23(10):2028-45.

30. Dionne CE, Dunn KM, Croft PR, Nachemson AL, Buchbinder R, Walker BF, et al. A consensus approach toward the standardization of back pain definitions for use in prevalence studies. Spine (Phila Pa 1976). 2008;33(1): 95-103.

31. Eubank BH, Mohtadi NG, Lafave MR, Wiley JP, Bois AJ, Boorman RS, et al. Using the modified Delphi method to establish clinical consensus for the diagnosis and treatment of patients with rotator cuff pathology. BMC Med Res Methodol. 2016;16:56.

32. Genevay S, Courvoisier DS, Konstantinou K, Kovacs FM, Marty M, Rainville J, et al. Clinical classification criteria for radicular pain caused by lumbar disc herniation: the radicular pain caused by disc herniation (RAPIDH) criteria. Spine J. 2017;17(10):1464-71

33. Geraets JJ, Geijer RM, Goudswaard AN. Dutch College of General Practitioners' practice guideline on symptoms of the hand and wrist: a summary. Ned Tijdschr Geneeskd. 2010;154:A1795.

34. Graham B, Regehr G, Naglie G, Wright JG. Development and validation of diagnostic criteria for carpal tunnel syndrome. J Hand Surg Am. 2006;31(6): 919-24.

35. Huang D, Liu YQ, Liang LS, Lin XW, Song T, Zhuang ZG, et al. The Diagnosis and therapy of degenerative knee joint disease: expert consensus from the Chinese pain medicine panel. Pain Res Manag. 2018:2018:2010129.

36. Keith MW, Masear V, Chung K, Maupin K, Andary M, Amadio PC, et al. Diagnosis of carpal tunnel syndrome. J Am Acad Orthop Surg. 2009;17(6): 389-96.

37. Koes BW, Sanders RJ, Tuut MK. Kwaliteitsinstituut voor de Gezondheidszorg CBO. The Dutch Institute for Health Care Improvement (CBO) guideline for the diagnosis and treatment of aspecific acute and chronic low back complaints]. Ned Tijdschr Geneeskd. 2004;148(7):310-4.

38. Koes BW, van Tulder M, Lin CW, Macedo LG, McAuley J, Maher C. An updated overview of clinical guidelines for the management of non-specific low back pain in primary care. Eur Spine J. 2010;19(12):2075-94

39. Koes BW, van Tulder MW, Ostelo R, Kim Burton A, Waddell G. Clinical guidelines for the management of low back pain in primary care: an international comparison. Spine (Phila Pa 1976). 2001;26(22):2504-13 discussion 13-4

40. Koes BW, van Tulder MW, Thomas S. Diagnosis and treatment of low back pain. BMJ. 2006;332(7555):1430-4.

41. Laerum E, Brox Jl, Werner EL. Low back pain--still a clinical challenge. Tidsskr Nor Laegeforen. 2010;130(22):2248-51. 
42. Leyland KM, Gates LS, Nevitt M, Felson D, Bierma-Zeinstra SM, Conaghan $P G$, et al. Harmonising measures of knee and hip osteoarthritis in population-based cohort studies: an international study. Osteoarthr Cartil. 2018;26(7):872-9.

43. Luyten FP, Bierma-Zeinstra S, Dell'Accio F, Kraus VB, Nakata K, Sekiya I, et al. Toward classification criteria for early osteoarthritis of the knee. Semin Arthritis Rheum. 2018;47(4):457-63.

44. Ma K, Zhuang ZG, Wang L, Liu XG, Lu LJ, Yang XQ, et al. The Chinese Association for the Study of pain (CASP): consensus on the assessment and Management of Chronic Nonspecific low Back Pain. Pain Res Manag. 2019; 2019:8957847

45. Martel-Pelletier J, Maheu E, Pelletier JP, Alekseeva L, Mkinsi O, Branco J, et al. A new decision tree for diagnosis of osteoarthritis in primary care: international consensus of experts. Aging Clin Exp Res. 2019;31(1):19-30.

46. Migliore A, Scire CA, Carmona L, Herrero-Beaumont G, Bizzi E, Branco J, et al. The challenge of the definition of early symptomatic knee osteoarthritis: a proposal of criteria and red flags from an international initiative promoted by the Italian Society for Rheumatology. Rheumatol Int. 2017;37(8):1227-36.

47. Negrini S, Giovannoni S, Minozzi S, Barneschi G, Bonaiuti D, Bussotti A, et al. Diagnostic therapeutic flow-charts for low back pain patients: the Italian clinical guidelines. Eura Medicophys. 2006;42(2):151-70.

48. O'Connell NE, Cook CE, Wand BM, Ward SP. Clinical guidelines for low back pain: a critical review of consensus and inconsistencies across three major guidelines. Best Pract Res Clin Rheumatol. 2016;30(6):968-80.

49. Oliveira CB, Maher CG, Pinto RZ, Traeger AC, Lin CC, Chenot JF, et al. Clinical practice guidelines for the management of non-specific low back pain in primary care: an updated overview. Eur Spine J. 2018;27(11):2791-803.

50. Patijn J, Vallejo R, Janssen M, Huygen F, Lataster A, van Kleef M, et al. Carpal tunnel syndrome. Pain Pract. 2011;11(3):297-301.

51. Reijman M, Hazes JM, Koes BW, Verhagen AP, Bierma-Zeinstra SM. Validity, reliability, and applicability of seven definitions of hip osteoarthritis used in epidemiological studies: a systematic appraisal. Ann Rheum Dis. 2004;63(3): 226-32.

52. Reith W. Nonspecific low back pain and chronification. Radiologe. 2020; 60(2):117-22.

53. Schumaier A, Kovacevic D, Schmidt C, Green A, Rokito A, Jobin C, et al. Defining massive rotator cuff tears: a Delphi consensus study. J Shoulder Elb Surg. 2020;29(4):674-80.

54. Stanton TR, Latimer J, Maher CG, Hancock MJ. A modified Delphi approach to standardize low back pain recurrence terminology. Eur Spine J. 2011; 20(5):744-52.

55. Swierstra BA, Bijlsma JW, de Beer JJ, Kuijpers T, Dutch MA. Guideline 'Diagnostics and treatment of osteoarthrosis of the hip and knee'. Ned Tijdschr Geneeskd. 2009;153:B39.

56. Verburg AF, Schaafstra A, Spinnewijn WE, Kroes BW, Bouma M, Burgers JS. Revised NHG practice guideline 'Lumbosacral radicular syndrome'. Ned Tijdschr Geneeskd. 2015;159:A9122.

57. Zhang W, Doherty M, Peat G, Bierma-Zeinstra MA, Arden NK, Bresnihan B, et al. EULAR evidence-based recommendations for the diagnosis of knee osteoarthritis. Ann Rheum Dis. 2010;69(3):483-9.

58. Lenderink AF, Zoer I, van der Molen HF, Spreeuwers D, Frings-Dresen MH, van Dijk FJ. Review on the validity of self-report to assess work-related diseases. Int Arch Occup Environ Health. 2012;85(3):229-51.

59. Hagberg M, Violante FS, Bonfiglioli R, Descatha A, Gold J, Evanoff B, et al. Prevention of musculoskeletal disorders in workers: classification and health surveillance - statements of the Scientific Committee on Musculoskeletal Disorders of the International Commission on Occupational Health. BMC Musculoskelet Disord. 2012;13:109.

60. Palmer KT, Smedley J. Work relatedness of chronic neck pain with physical findings--a systematic review. Scand J Work Environ Health. 2007;33(3):165-91.

61. Hulshof CTJ, Colosio C, Daams JG, Ivanov ID, Prakash KC, Kuijer P, et al. WHO/ILO work-related burden of disease and injury: protocol for systematic reviews of exposure to occupational ergonomic risk factors and of the effect of exposure to occupational ergonomic risk factors on osteoarthritis of hip or knee and selected other musculoskeletal diseases. Environ Int. 2019;125:554-66.

62. van der Beek AJ, Dennerlein JT, Huysmans MA, Mathiassen SE, Burdorf A, van Mechelen W, et al. A research framework for the development and implementation of interventions preventing work-related musculoskeletal disorders. Scand J Work Environ Health. 2017;43(6):526-39.
63. van der Molen HF, Foresti C, Daams JG, Frings-Dresen MHW, Kuijer P. Workrelated risk factors for specific shoulder disorders: a systematic review and meta-analysis. Occup Environ Med. 2017;74(10):745-55.

64. Verbeek J, Mischke C, Robinson R, ljaz S, Kuijer P, Kievit A, et al. Occupational exposure to knee loading and the risk of osteoarthritis of the knee: a systematic review and a dose-response meta-analysis. Saf Health Work. 2017;8(2):130-42.

65. Yung M, Dale AM, Kapellusch J, Bao S, Harris-Adamson C, Meyers AR, et al. Modeling the effect of the 2018 revised $\mathrm{ACGIH}((\mathrm{R}))$ hand activity threshold limit value((R)) (TLV) at reducing risk for carpal tunnel syndrome. J Occup Environ Hyg. 2019;16(9):628-33.

66. Seidler A, Luben L, Hegewald J, Bolm-Audorff U, Bergmann A, Liebers F, et al. Dose-response relationship between cumulative physical workload and osteoarthritis of the hip - a meta-analysis applying an external reference population for exposure assignment. BMC Musculoskelet Disord. 2018;19(1):182.

67. Kuijer P, Verbeek JH, Seidler A, Ellegast R, Hulshof CTJ, Frings-Dresen MHW, et al. Work-relatedness of lumbosacral radiculopathy syndrome: review and dose-response meta-analysis. Neurology. 2018;91(12):558-64.

68. (WHO) WHO. International Classification of Diseases 11th Revision (ICD-11) 2019. https://icd.who.int/en.

69. The L. Icd-11. Lancet. 2019;393(10188):2275.

70. Humphrey-Murto S, Varpio L, Wood TJ, Gonsalves C, Ufholz LA, Mascioli K, et al. The use of the Delphi and other consensus group methods in medica education research: a review. Acad Med. 2017;92(10):1491-8.

71. Diamond IR, Grant RC, Feldman BM, Pencharz PB, Ling SC, Moore AM, et al. Defining consensus: a systematic review recommends methodologic criteria for reporting of Delphi studies. J Clin Epidemiol. 2014;67(4):401-9.

72. Lange T, Kopkow C, Lutzner J, Gunther KP, Gravius S, Scharf HP, et al. Comparison of different rating scales for the use in Delphi studies: different scales lead to different consensus and show different test-retest reliability. BMC Med Res Methodol. 2020;20(1):28.

73. Hauer KE, Cate OT, Boscardin CK, lobst W, Holmboe ES, Chesluk B, et al. Ensuring resident competence: a narrative review of the literature on group decision making to inform the work of clinical competency committees. J Grad Med Educ. 2016;8(2):156-64.

\section{Publisher's Note}

Springer Nature remains neutral with regard to jurisdictional claims in published maps and institutional affiliations.
Ready to submit your research? Choose BMC and benefit from:

- fast, convenient online submission

- thorough peer review by experienced researchers in your field

- rapid publication on acceptance

- support for research data, including large and complex data types

- gold Open Access which fosters wider collaboration and increased citations

- maximum visibility for your research: over $100 \mathrm{M}$ website views per year

At BMC, research is always in progress.

Learn more biomedcentral.com/submissions 